take full weight and, if socially possible, were discharged from hospital. The fixator was removed when adequate radiographic callus was visible, usually at 12 to 16 weeks. Results. All five fractures united in good position with no refractures after a minimum follow-up of two years. No knee replacements have loosened as a result of the fracture, and the patients have regained their original $0^{\circ}$ to $80^{\circ}$ range of knee movement.

They each had minor pin-track infections, requiring treatment by simple dressings and oral antibiotics, but no pin was removed and all the fractures healed well after fixator removal.

Illustrative case. An 86-year-old woman fell and sustained a spiral fracture above her knee prosthesis (Fig. 1). Internal fixation failed (Fig. 2). The plate and accessible screws were removed and a Portsmouth fixator applied. Union and consolidation were very satisfactory (Fig. 3). Discussion. Late femoral shaft fracture after a Stanmore total knee replacement remains a difficult management problem. Grimer, Karpinski and Edwards (1984) treated one case by internal fixation, but it failed to unite. Another was treated by traction and an external fixator, but developed infected nonunion and came to above- knee amputation. Lettin et al (1984) reported six cases, a $2.9 \%$ incidence in their series of knee replacements. Three had loose femoral components and required revision with custom-made prostheses. Merkel and Johnson (1986) successfully used external fixation for three of 36 supracondylar femoral fractures occurring after resurfacing total knee replacements.

Our use of the Portsmouth external fixator has been very successful with sound union in all five patients by 16 weeks, and no major complications or refractures. This type of management is recommended.

No benefits in any form have been received or will be received from a commercial party related directly or indirectly to the subject of this article.

\section{REFERENCES}

Edge AJ, Denham RA. The Portsmouth method of external fixation of complicated tibial fractures. Injury 1979; 11 :13-18.

Grimer RJ, Karpinski MRK, Edwards AN. The long-term results of Stanmore total knee replacements. J Bone Joint Surg [Br] 1984; 66-B: $: 55-62$.

Lettin AWF, Kavanagh TG, Scales JT. The long-term results of Stanmore total knee replacements. J Bone Joint Surg [Br] 1984; 66-B:349-54.

Merkel KD, Johnson EW. Supracondylar fracture of the femur after total knee arthroplasty. J Bone Joint Surg [Am] 1986; 68-A :29-43.

\title{
HOW THE SIMMONDS-THOMPSON TEST WORKS
}

\author{
B. W. SCOTT, A. AL CHALABI
}

Testing for rupture of the calcaneal tendon by squeezing the calf was first described by Simmonds (1957). Thompson (1962) had observed this effect some two years earlier in 1955. It is accepted that the SimmondsThompson test is pathognomonic for complete rupture, but its mechanism is not clear.

Investigation. We used an ultrasound machine with a $7.5 \mathrm{MHz}$ linear probe to examine dynamic images of the calf in two young adults. With transverse compression, the gastrocnemius was clearly seen to move proximally, corresponding to the movement at the ankle. The soleus was more difficult to visualise, but no proximal movement of the muscle could be seen.

By contrast, Thompson and Doherty (1962) had found, in cadavers, that the squeeze test became positive

B. W. Scott, FRCS, Orthopaedic Registrar

A. Al Chalabi, FRCS, Associate Specialist

Coventry and Warwickshire Hospital, Stoney Stanton Road, Coventry CV1 4FH, England.

Correspondence to $\mathrm{Mr}$ B. W. Scott at $2 \mathrm{St}$ Margaret's Drive, Roundhay, Leeds LS8 1 RU, England.

(C) 1992 British Editorial Society of Bone and Joint Surgery $0301-620 X / 92,2 R 42 \$ 2.00$

J Bone Joint Surg [ Br] 1992; 74-B:314-5.
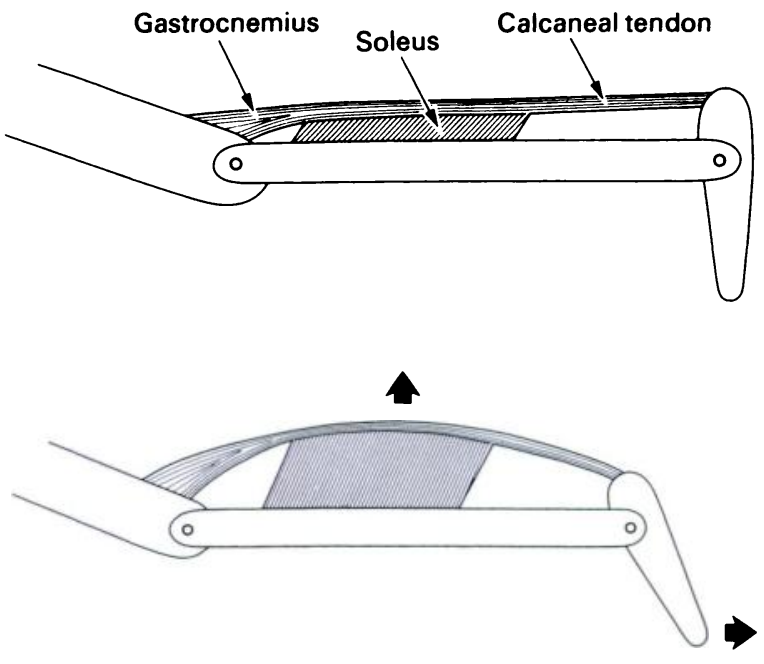

Fig. 1

(no plantar flexion) when the soleus alone was divided. To elucidate this we dissected three fresh above-knee amputation specimens and separated the gastrocnemius tendon from the soleus down to about $10 \mathrm{~cm}$ above the calcaneum where the fibres became blended into one 
tendon. Squeezing the calf was seen to deform the fleshy soleus causing the overlying gastrocnemius tendon to bow away from the tibia resulting in plantar flexion (Fig. 1). There was no longitudinal movement of the soleus while the gastrocnemius muscle bellies moved about $1 \mathrm{~cm}$ proximally, confirming our ultrasound findings.

When the soleus tendon was divided the proximal movement of the gastrocnemius, due to direct pressure on the tapering bellies, produced only a small amount of plantar flexion. Division of the gastrocnemius tendon alone did not prevent full plantar flexion on calf compression.

Conclusion. The result of the Simmonds-Thompson test principally reflects the integrity of the soleus musculotendinous unit. Plantar flexion is caused by posterior bowing of the calf tendons and, to a less extent, by proximal displacement of the bellies of the gastrocnemius.

No benefits in any form have been received or will be received from a commercial party related directly or indirectly to the subject of this article.

\section{REFERENCES}

Simmonds FA. The diagnosis of the ruptured Achilles tendon. The Practitioner 1957; 179:56-8.

Thompson TC. A test for rupture of the tendo Achillis. Acta Orthop Scand 1962; 32:461-5.

Thompson TC, Doherty JH. Spontaneous rupture of tendon of Achilles: a new clinical diagnostic test. $J$ Trauma $1962 ; 2: 126-9$.

\title{
PROMINENCE OF THE CALCANEUS: LATE RESULTS OF BONE RESECTION
}

\author{
H. M. HUBER
}

Undue prominence of the posterosuperior edge of the calcaneal tuberosity (Fig. 1) can lead to mechanical irritation by footwear, and to painful bursitis. Haglund (1927) recommended radical resection of this part of the calcaneus when conservative treatment failed, but there is uncertainty about the amount of bone which should be removed.

Patients and methods. From 1970 to 1985 we treated 120
Of these, 98 patients completed a questionnaire after an average of 8.3 years ( 3 to 18$)$. The 18 patients with some residual symptoms were also reviewed clinically and radiologically. We recorded the height of any bony ridge left after resection, measuring from the upper margin of the insertion of the calcaneal tendon (Fig. 2), which is seen on a lateral radiograph as a thickening of the cortex.

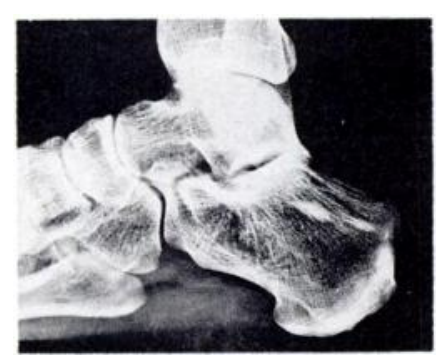

Fig. 1
Figure 1-Prominence of the posterosuperior edge of the calcaneal tuberosity. The insertion of the calcaneal tendon is marked by a thickening of the cortex. Figure 2 - The height of the ridge is the distance from the calcaneal tendon insertion (A) to the posterosuperior ridge of the calcaneus (B). The shape of the surface after complete removal of the calcaneal ridge (C).

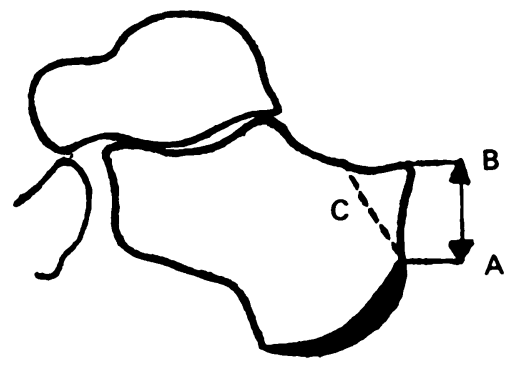

Fig. 2 patients at the Orthopaedic University Hospital Balgrist in Zurich by resection of the posterosuperior calcaneal tuberosity. Their average age was 15.5 years (12 to 32 ); 72 were female, 48 were male and most had bilateral operations. We used a lateral approach 1 to $2 \mathrm{~cm}$ anterior to the calcaneal tendon (Inman 1973).

H. M. Huber, MD, Orthopaedic Surgeon

Hôpital de la Ville, Rue du Chasseral, CH-2300 La Chaux-de-Fonds, Switzerland.

(C) 1992 British Editorial Society of Bone and Joint Surgery 0301-620X/92/2R $47 \$ 2.00$

J Bone Joint Surg [ Br] 1992; 74-B:315-6.
Results. Eighty of the 98 patients were completely free of problems in both feet, 14 had minor residual complaints, two had no improvement and two had been made worse. The average height of the ridge pre-operatively in all 98 patients was $28 \mathrm{~mm}$ (24 to 32 ); postoperatively it was $8 \mathrm{~mm}$ ( 0 to 32 ). In the 80 patients with complete relief of symptoms the mean height was $7 \mathrm{~mm}$ (0 to 13).

Of the 18 patients with residual symptoms, six had painful superficial scars. Seven had persistent pressure problems: five of these had an average postoperative ridge height of $18 \mathrm{~mm}$ ( 15 to 32 ), and two had calcification in the resected zone. The other five patients with pain had calcaneal tendinitis due to too steep a resection. 